\title{
Pemanfaatan Kitosan untuk Mengendalikan Antraknosa pada Pepaya (Colletotrichum gloeosporioides) dan Meningkatkan Daya Simpan Buah
}

\author{
Use of Chitosan to Control Anthracnose on Papaya \\ (Colletotrichum gloeosporioides) and to Improve \\ the Length of Fruit Storage
}

\author{
Hamdayanty, Rita Yunita, Nurul Nisa Amin, Tri Asmira Damayanti* \\ Institut Pertanian Bogor, Bogor 16680
}

\begin{abstract}
ABSTRAK
Antraknosa (Colletotrichum gloeosporioides) merupakan penyakit pascapanen penting pada buahbuahan. Kitosan yang digunakan untuk melapisi kulit buah pepaya ditujukan untuk mengurangi infeksi C. gloeosporiodes dan meningkatkan daya simpan buah pepaya. C. gloeosporioides diisolasi dari buah pepaya matang. Uji secara in vitro dilakukan dengan mencampurkan kitosan konsentrasi $0.05,0.1,0.25$, $0.5,0.75$, dan $1 \%$ dalam medium potato dextrose agar dan konsentrasi yang sama digunakan untuk uji secara in vivo pada buah pepaya. Pada uji in vitro, konsentrasi kitosan $0.75-1 \%$ mampu menghambat pertumbuhan $C$. gloeosporioides sebesar 72.17-85.21\%. Penyemprotan kitosan untuk melapisi permukaan buah pepaya mampu menekan kejadian dan keparahan penyakit antraknosa, sedangkan kitosan konsentrasi $0.75 \%$ selain dapat menekan kejadian dan keparahan penyakit antraknosa, juga meningkatkan daya simpan buah 2 kali lebih lama dibandingkan dengan kontrol.
\end{abstract}

Kata kunci: antraknosa, Colletotrichum gloeosporioides, daya simpan buah, kitosan, pepaya

\section{ABSTRACT}

Anthracnose (Colletotrichum gloeosporioides) is an important disease infecting fleshy fruits. The efficacy of chitosan to suppress C. gloeosporioides infection and its ability to increase the length of fruit storage was evaluated. C. gloeosporioides was isolated and purified from mature papaya. Chitosan was mixed in the potato dextrose agar, and sprayed on the surface of papaya fruit with the concentration of $0.05,0.1,0.25,0.5,0.75$ and $1 \%$. It showed that chitosan concentration of $0.75-1 \%$ inhibited $C$. gloeosporioides growth in vitro up to $72.17-85.21 \%$. Application of chitosan on fruit at concentration of $0.25 \%$ suppressed the disease incidence and severity; whereas chitosan concentration of $0.75 \%$ was able to suppress the disease incidence, severity, and increase the length of fruit storage twice longer than control.

Key words: anthracnose, chitosan, Colletotrichum gloeosporioides, papaya, the length of storage

*Alamat penulis korespondensi: Departemen Proteksi Tanaman, Fakultas Pertanian, Institut Pertanian Bogor, Jalan Kamper, Kampus IPB, Darmaga, Bogor 16680

Tel: 0251-8629364, Faks: 0251-8629362, Surel: triadys@ipb.ac.id 


\section{PENDAHULUAN}

Pepaya merupakan buah tropik yang mempunyai arti ekonomi dan memiliki kandungan gizi yang sangat tinggi. Berdasarkan data Badan Pusat Statistik (2011), produksi pepaya di Indonesia mengalami fluktuasi dari tahun 2008 hingga 2010 karena beberapa hal, salah satunya ialah serangan antraknosa yang disebabkan oleh Colletotrichum gloeosporioides. Kejadian antraknosa dapat mencapai $70 \%$ dan dilaporkan merupakan penyebab utama kehilangan hasil pascapanen pada buah pepaya California (Kementan 2011).

Permasalahan yang dihadapi produsen dalam usaha pengembangan produksi dan kualitas buah pepaya ialah daya simpan pepaya yang cukup rendah. Hal ini juga menjadi masalah bagi ekspor pepaya Indonesia. Menurut Harianingsih (2010), daya simpan yang rendah ini dapat dipengaruhi oleh difusi gas $\mathrm{CO}_{2}$ ke dalam dan ke luar buah yang terjadi melalui lentisel yang tersebar di permukaan buah. Perkembangan penyakit antraknosa dan proses metabolisme pada buah dapat dihambat dengan penggunaan bahan pelapis (coating). Edible coating adalah suatu metode pemberian lapisan tipis pada permukaan buah untuk menghambat keluarnya gas, uap air, dan kontak dengan oksigen sehingga proses pemasakan dan pencokelatan buah dapat diperlambat. Lapisan yang ditambahkan di permukaan buah ini tidak berbahaya bila ikut dikonsumsi bersama buah.

Kitosan adalah polisakarida berasal dari limbah kulit/cangkang Crustaceae. Kitosan diketahui dapat menginduksi respons ketahanan tanaman terhadap infeksi patogen (Hadrami et al. 2010). Selain itu, kitosan dapat digunakan untuk pelapis buah tomat (Ghaouth et al. 1991) dan leci (Dong et al. 2004). Kitosan dapat menginduksi enzim kitinase yang dapat mendegradasi kitin, yang merupakan penyusun utama dinding sel cendawan sehingga dapat digunakan sebagai fungisida (Ghaouth et al. 1991). Menurut Pamekas (2009), kitosan mampu menghambat pertumbuhan Colletotrichum musae melalui penghambatan perkecambahan konidium, memperkecil lebar hifa, memperpendek ruas hifa, dan menyebabkan hifa lisis.

Penyakit antraknosa dapat menyebabkan rendahnya kualitas buah pepaya. Penggunaan pestisida sintetik pada buah dapat mengakibatkan resiko kesehatan pada konsumen. Daya simpan pepaya yang cukup rendah juga menjadi penghalang untuk kegiatan pengiriman baik dalam maupun luar negeri. Untuk menghindari penggunaan pestisida sintetik maka dipilih alternatif pengendalian antraknosa yang ramah lingkungan menggunakan kitosan sebagai pelapis.

Tujuan penelitian ini adalah mengetahui konsentrasi kitosan yang efektif untuk meningkatkan daya simpan buah pepaya agar tahan terhadap penyakit antraknosa.

\section{BAHAN DAN METODE}

\section{Sumber Inokulum Colletotrichum gloeos- porioides}

C. gloeosporioides diisolasi dari pepaya yang bergejala khas antraknosa pada medium potato dextrose agar (PDA). Setelah pengamatan mikroskopi menunjukkan ciri-ciri C. gloeosporioides, kemudian cendawan dimurnikan pada medium PDA.

\section{Pengujian Keefektifan Kitosan Menekan $C$. gloeosporioides Secara in Vitro}

Kitosan diperoleh dari Fakultas Perikanan Ilmu Kelautan IPB. Konsentrasi kitosan dalam PDA yang digunakan ialah 0.05, 0.1, $0.25,0.5,0.75,1.0$ dan kontrol. Isolat $C$. gloeosporioides ditumbuhkan pada medium PDA yang mengandung kitosan. Setiap perlakuan konsentrasi kitosan terdiri atas 3 ulangan.

Pengamatan keefektifan kitosan dilakukan setelah 6 hari dengan mengukur diameter pertumbuhan cendawan $C$. gloeosporioides dan dibandingkan dengan kontrol. Tingkat hambatan relatif (THR) kitosan dihitung dengan rumus: 


$$
\mathrm{THR}=\frac{(\mathrm{Dk}-\mathrm{Dp})}{\mathrm{Dk}} \times 100 \%, \text { dengan }
$$

$\mathrm{Dk}$, diameter kontrol dan $\mathrm{Dp}$, diameter perlakuan.

Pengujian Keefektifan Kitosan Menekan $C$. gloeosporioides Secara in Vivo

Pepaya disterilkan permukaannya dengan merendam dalam larutan natrium hipoklorit 1\% selama 1 menit, kemudian buah dibilas dengan air steril 2 kali masing-masing selama 1 menit dan dikeringanginkan. Larutan kitosan disemprotkan ke seluruh permukaan buah pepaya sesuai perlakuan menggunakan sprayer. Kontrol disemprot dengan air steril. Pepaya perlakuan dilukai dengan jarum steril dan diinokulasi $C$. gloeosporioides pada tiga titik, masing-masing perlakuan terdiri atas 3 buah. Pepaya disimpan di atas baki steril berukuran $40 \mathrm{~cm}$ x $30 \mathrm{~cm}$ dan baki dibungkus plastik bening untuk menjaga kelembapan. Percobaan yang sama diulang sebanyak 4 kali.

Persiapan pengujian pengaruh kitosan terhadap daya simpan pepaya dilakukan sama seperti uji keefektifan kitosan dalam menekan antraknosa, namun pepaya tidak diinokulasi C. gloeosporioides.

Pengamatan yang dilakukan meliputi tingkat kematangan buah, daya simpan (hari), kejadian penyakit (\%), dan keparahan penyakit (\%) buah pepaya. Pengamatan daya simpan buah dilakukan pada hari ke-3 dan hari ke6. Daya simpan buah ditentukan berdasarkan persentasi tingkat kematangan buah pepaya (Gambar 1). Kejadian penyakit pada tanaman dapat diketahui dengan menghitung jumlah buah uji yang sakit dan membandingkannya dengan jumlah buah uji yang digunakan. Kejadian penyakit (KP) diamati pada hari ke10 dengan rumus:

$$
\mathrm{KP}=\frac{\sum \text { buah terinfeksi penyakit }}{\sum \text { buah yang diamati }} \times 100 \%
$$

Keparahan penyakit (I) dihitung dengan rumus:

$$
I=\frac{n}{N} \times 100 \% \text {, dengan }
$$

n, jumlah sampel per kategori x skor keparahan; $\mathrm{N}$, jumlah sampel yang diamati $\mathrm{x}$ skor tertinggi.

Skor tiap kategori serangan mengikuti ketentuan sebagai berikut. 0: tidak bergejala, 1: Bercak ringan pada buah (1-19\%), 2: Bercak sedang pada buah (mencapai 20\%), 3: Bercak sedang disertai busuk ringan pada buah, 4: Bercak luas dan busuk pada buah.

\section{Analisis Data}

Rancangan percobaan yang digunakan adalah rancangan acak lengkap. Perlakuan terdiri atas 7 konsentrasi kitosan, yaitu 0.05 , $0.1,0.25,0.5,0.75,1 \%$, dan kontrol $(0 \%)$. Data penghambatan kitosan dan daya simpan buah dianalisis menggunakan ANOVA dengan program SAS versi 9.1. Selanjutnya, perlakuan yang memberikan pengaruh nyata diuji lanjut dengan Duncan Multiple Range Test pada taraf $\alpha=5 \%$.

\section{HASIL}

\section{Sumber Inokulum Colletotrichum gloeos- porioides}

Koloni cendawan yang diisolasi dari buah pepaya berupa miselium berwarna putih (Gambar 2a), hialin, bersekat, dan bercabang (Gambar 2b). Konidium berupa sel tunggal, hialin, dan kedua ujung konidium tumpul (Gambar 2c). Berdasarkan pada morfologi miselium dan konidium yang diamati maka cendawan ini diidentifikasi sebagai $C$. gloeosporioides (Tasiwal 2008).

\section{Efektivitas Kitosan Menekan C. gloeospori- oides Secara in Vitro}

Secara umum, semakin tinggi konsentrasi kitosan yang digunakan maka kitosan akan semakin efektif menekan pertumbuhan C. gloeosporioides. Konsentrasi kitosan sampai $0.25 \%$ tidak mampu menghambat pertumbuhan $C$. gloeosporioides secara nyata jika dibandingkan dengan kontrol; tingkat hambatan relatif (THR) kurang dari 24.25\%. 


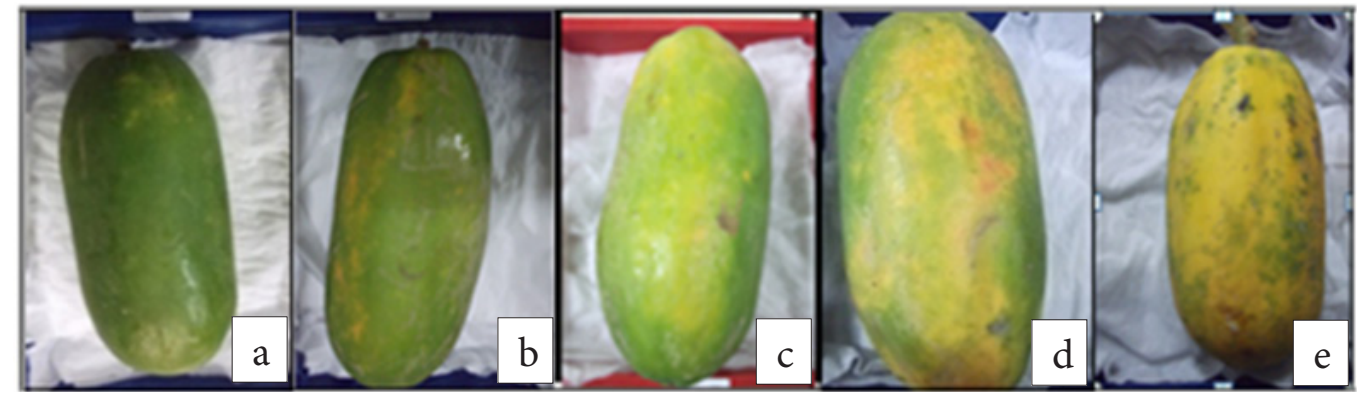

Gambar 1 Persentasi tingkat kematangan buah pepaya. a, 30\%; b, 40\%; c, 50\%; d, 60\%; e, $85 \%$, ditunjukkan oleh menguningnya seluruh kulit buah.

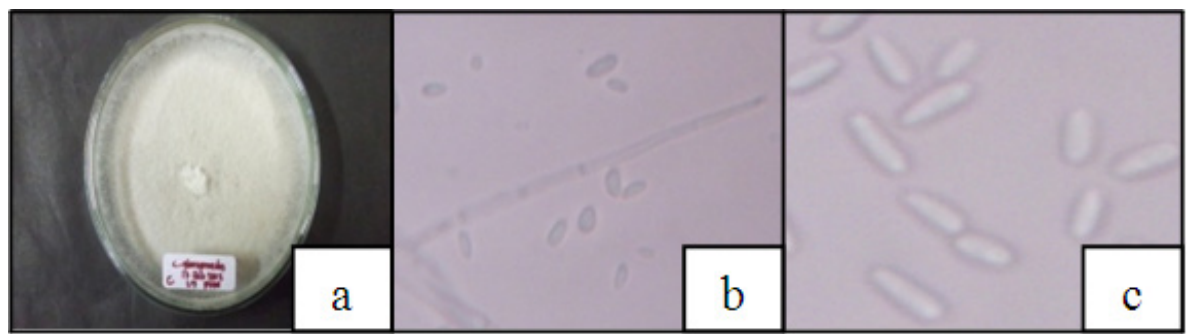

Gambar 2 Colletotrichum gloeosporioides. a, isolat murni pada PDA; dan b, miselium dan konidia (perbesaan 100X); serta c, konidia cendawan (400X).

THR semakin meningkat pada penggunaan kitosan konsentrasi $0.5-1.0 \%$. Konsentrasi $0.75 \%$ sudah cukup efektif menghambat pertumbuhan C. gloeosporioides sampai mencapai $72.1 \%$, dan pada konsentrasi $1.0 \%$ mencapai $85.21 \%$ (Tabel 1).

Efektivitas Kitosan Menekan C. gloeosporioides Secara in Vivo

Pengujian in vivo menunjukkan bahwa kitosan dapat menghambat kejadian dan keparahan penyakit antraknosa pada semua perlakuan. Pemberian kitosan konsentrasi yang rendah, yaitu $0.05 \%$ dan $0.1 \%$, sudah dapat mengurangi kejadian dan keparahan penyakit jika dibandingkan dengan kontrol dan tidak satu pun buah pepaya menunjukkan gejala penyakit antraknosa pada perlakuan konsentrasi kitosan 0.25-1.0\% (Gambar 3).

\section{Pengaruh Kitosan Terhadap Daya Simpan Buah Pepaya}

Perlakuan kitosan mempengaruhi tingkat kematangan buah. Pada hari ketiga setelah perlakuan, konsentrasi kitosan 0.05-0.25\% belum mampu menghambat kematangan buah dibandingkan dengan kontrol. Kematangan
Tabel 1 Pengaruh kitosan terhadap pertumbuhan Colletotrichum gloeosporioides secara in vitro

\begin{tabular}{lcc}
\hline $\begin{array}{l}\text { Kitosan } \\
(\%)\end{array}$ & $\begin{array}{c}\text { Diameter } \\
\text { cendawan }(\mathrm{mm})^{\mathrm{a}}\end{array}$ & $\begin{array}{c}\text { Tingkat hambat } \\
\text { relatif }(\%)^{\mathrm{b}}\end{array}$ \\
\hline Kontrol & $38.33 \mathrm{ab}$ & - \\
0.05 & $41.00 \mathrm{a}$ & -6.97 \\
0.10 & $32.67 \mathrm{abc}$ & 14.77 \\
0.25 & $29.00 \mathrm{bc}$ & 24.34 \\
0.50 & $25.33 \mathrm{c}$ & 33.92 \\
0.75 & $10.67 \mathrm{~d}$ & 72.17 \\
1.00 & $5.67 \mathrm{~d}$ & 85.21 \\
\hline
\end{tabular}

a, angka yang diikuti huruf yang berbeda pada kolom yang sama menunjukkan hasil yang berbeda nyata (uji selang ganda Duncan $\alpha=5 \%$ ); b, THR = tingkat hambatan relatif terhadap kontrol

buah tampak terhambat pada penggunaan kitosan $0.5 \%-1.0 \%$.

Pada hari keenam setelah perlakuan, konsentrasi kitosan $0.75 \%$ paling efektif dalam menghambat proses kematangan buah secara nyata jika dibandingkan dengan kontrol atau perlakuan lain (0-0.25\%), walaupun tidak berbeda nyata dengan perlakuan konsentrasi 0.5 dan 1.0\% (Gambar 4). Kematangan buah kontrol mencapai $80 \%$, sedangkan pepaya perlakuan konsentrasi kitosan $0.75 \%$ baru 


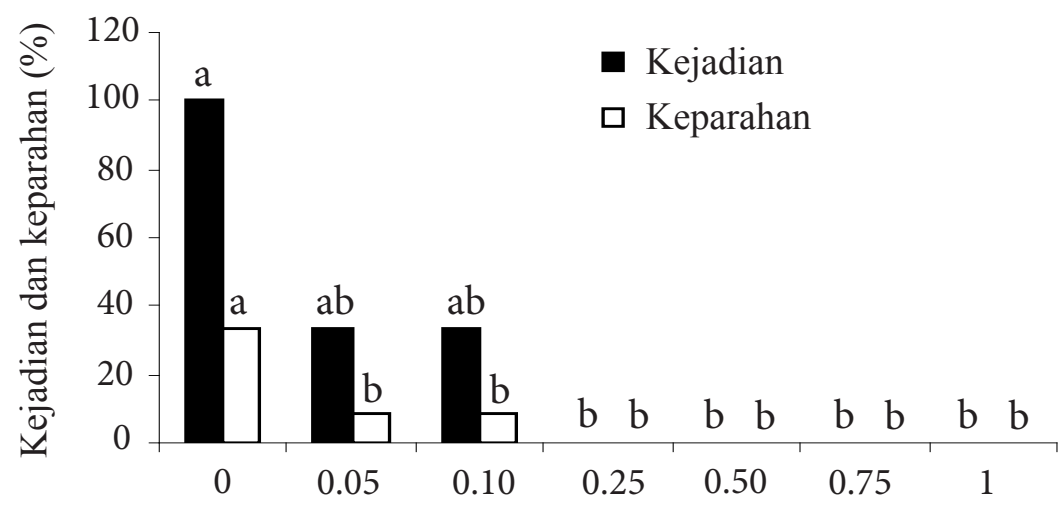

Konsentrasi kitosan (\%)

Gambar 3 Pengaruh kitosan terhadap kejadian dan keparahan penyakit antraknosa.

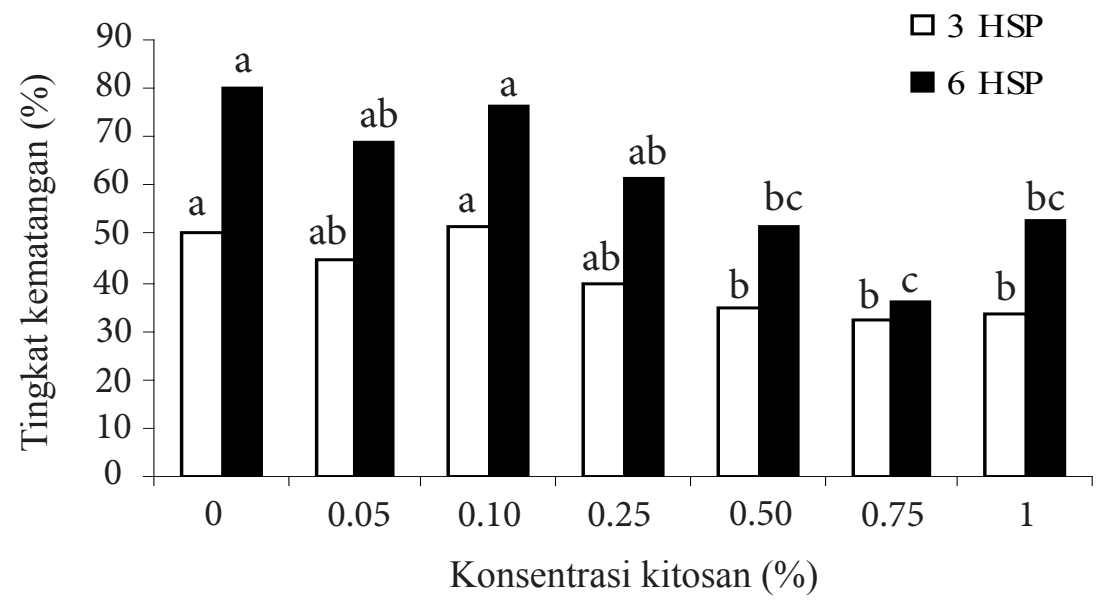

Gambar 4 Pengaruh kitosan terhadap tingkat kematangan buah pepaya. HSP, Hari setelah perlakuan.

mencapai kematangan 36.25\%. Hal ini menunjukkan perlakuan konsentrasi $0.75 \%$ mampu menghambat kematangan buah 2 kali lebih lambat dibandingkan dengan kontrol.

\section{PEMBAHASAN}

Perlakuan kitosan secara umum mampu menekan infeksi C. gloeosporioides secara in vitro dengan THR yang semakin meningkat seiring dengan meningkatnya konsentrasi kitosan yang digunakan. Hal ini sejalan dengan hasil penelitian Rogis et al. (2007) yang menyebutkan bahwa semakin tinggi konsentrasi kitosan yang digunakan maka semakin besar pula penghambatan terhadap pertumbuhan $C$. musae. Secara in vivo, konsentrasi kitosan yang efektif untuk menekan kejadian dan keparahan penyakit sekaligus menghambat kematangan buah jika dibandingkan dengan kontrol atau perlakuan lain (0.05-0.25\%) adalah konsentrasi $0.75 \%$.

Penghambatan pertumbuhan cendawan terjadi karena kemampuan kitosan sebagai anticendawan. Dinding sel cendawan umumnya tersusun atas lapisan peptidoglikan dan lipopolisakarida yang merupakan lemak dan protein (Sugipriatini 2009). Menurut Restuati (2008), gugus asam amino dalam bentuk asetil amino $\left(\mathrm{HCOCH}_{3}\right)$ dan glukosamin $\left(\mathrm{C}_{6} \mathrm{H}_{9} \mathrm{NH}_{2}\right)$ dalam kitosan yang bermuatan positif dapat berikatan dengan bagian makromolekul bermuatan negatif pada permukaan sel cendawan. Hal ini menyebabkan apresorium dan pertumbuhan cendawan akan terhambat.

Kitosan sebagai pelapis pada permukaan buah pepaya dapat menghambat proses respirasi pada tingkat yang sangat rendah. Respirasi rendah dapat mengakibatkan pemecahan pati termasuk gula berjalan lambat 
sehingga semakin rendah respirasi buah maka proses kematangan buah semakin lambat (Restuati 2008). Kehilangan hasil akibat penyakit antraknosa yang tinggi dan rendahnya daya simpan buah pepaya menunjukkan besarnya potensi pemanfaatan kitosan dalam mendukung peningkatan kualitas dan kuantitas buah-buah yang diekspor dari Indonesia.

\section{UCAPAN TERIMA KASIH}

Penelitian ini dibiayai oleh program PKM DIKTI 2012. Ucapan terima kasih penulis sampaikan kepada Dr Ir Efi Toding Tondok, MScAgr atas bantuannya dalam mengidentifikasi sumber inokulum.

\section{DAFTAR PUSTAKA}

[BPS] Badan Pusat Statistik. 2011. Produksi buah-buahan di Indonesia. www.bps.goid/ tab_sub/view.php [diunduh 10 Agustus 2012].

Dong H, Cheng L, Tan J, Zheng K, Jiang Y. 2004. Effect of chitosan coating on quality and shelf life of peeled litchi fruit. J Food Eng. 64(3):355-358. doi: 10.1016/J. jfoodeng. 2003.11.003.

Ghaout AE, Aul J, Ponampalan R. 1991. Chitosan coating effect on storability and quality of fresh strawberries. J Food Sci. 56(6):1618-1620. doi: 10.111/J.1365-262 1.1991.tb08655.x.

Hadrami El A, Adam LR, Hadrami El I, Daayf F. 2010. Chitosan in plant protection. Marine Drugs. 8(4):968-987. doi:10.3390/ md8040968.
Harianingsih. 2010. Pemanfaatan limbah cangkang kepiting menjadi kitosan sebagai bahan pelapis (coater) pada buah stroberi [tesis]. Semarang (ID): Universitas Diponegoro.

[Kementan] Kementrian Pertanian. 2011. Budidaya Pepaya California. Semarang [ID]: Balai Pengkajian Teknologi Pertanian Jawa Tengah.

Pamekas T. 2009. Induksi Ketahanan Buah Pisang Ambon Curup terhadap Penyakit Pascapanen Antraknos dan Penundaan Kematangan dengan Aplikasi Kitosan. Yogyakarta (ID): Fakultas Pertanian, Universitas Gadjah Mada.

Rogis A, Pamekas T, Mucharromah. 2007. Karakteristik dan uji efikasi bahan senyawa alami chitosan terhadap patogen pascapanen antraknosa. JIPI. 9(1):58-63.

Sugipriatini D. 2009. Potensi penggunaan khamir dan kitosan untuk pengendalian busuk buah Lasiodiplodia theobromae pada buah mangga selama penyimpanan [tesis]. Bogor (ID): Institut Pertanian Bogor.

Restuati M. 2008. Perbandingan chitosan kulit udang dan kulit kepiting dalam menghambat pertumbuhan kapang Aspergillus flavus. Di dalam: Prosiding Seminar Nasional Sains dan Teknologi; 2008 Nov 17; Lampung (ID): Satek. hlm 582-590.

Tasiwal V. 2008. Studies on anthracnose - a postharvest disease of papaya [tesis]. Dharwad (IN): University of Agricultural Sciences. 